\title{
Hands-On Optics science camps and clubs
}

\section{Constance Walker, Robert Sparks, Stephen Pompea}

Constance E. Walker, Robert T. Sparks, Stephen M. Pompea, "Hands-On Optics science camps and clubs," Proc. SPIE 9665, Tenth International Topical Meeting on Education and Training in Optics and Photonics, 96650M (3 June 2007); doi: 10.1117/12.2207503

SDIE Event: Tenth International Topical Meeting on Education and Training in Optics and Photonics, 2007, Ottawa, Ontario, Canada 


\title{
Hands-On Optics Science Camps and Clubs
}

\author{
Constance E. Walker, Robert T. Sparks, and Stephen M. Pompea \\ National Optical Astronomy Observatory, 950 N. Cherry Ave., Tucson, Arizona, 85719 USA \\ Author Contact: Voice 520.318.8535,Email: cwalker@noao.edu
}

\begin{abstract}
Hands-On Optics (HOO) is a National Science Foundation funded program to bring optics education to traditionally underserved middle school students. We have developed six modules that teach students optics concepts through hands-on, inquiry-based activities. The modules have been used extensively in after-school and non-school settings such as in the Boys and Girls Clubs in South Tucson, Arizona and the Boys and Girls Club in Sells, Arizona on the Tohono O'odham reservation. We will describe these programs and the lessons learned in these settings. These modules also form the basis for a week-long optics camp that provides students with approximately 40 hours of instruction time in optics. We will provide an outline of the activities and concepts covered in the camp. These camps provide an ideal way to encourage interest in optics before career choices are developed.
\end{abstract}

\section{Introduction}

Hands-On Optics (HOO) is a four-year National Science Foundation funded program to bring optics education to traditionally underserved middle-school aged and younger students (ages 8-14) (Pompea et al. 2005a). We have developed six activity modules and classroom ready kits that teach students optics concepts through hands-on, inquiry-based activities. Our intent is to expose young children to optical phenomena to build scientific interest and literacy. Our belief is that this can be done quite effectively at science centers, after-school programs, in clubs, and in competitions (Pompea and Hawkins 2001, Pompea et. al. 2005b)

HOO has been a collaboration among the International Society for Optical Engineering (SPIE), in Bellingham, Washington; the Optical Society of America (OSA) in Washington, DC; and the National Optical Astronomy Observatory (NOAO) in Tucson, Arizona. HOO was originally designed for middle school-aged students who are in after-school or science museum programs. HOO has also been used formally in classrooms. This paper addresses the use of HOO in an informal setting- Boys and Girls Clubs and camps devoted to optics. At Boys and Girls Clubs, the HOO program has been successfully adapted to a younger age group ( 8 years old and up).

Since the Summer of 2006, the Hands-On Optics program has successfully partnered with the Boys and Girls Club of South Tucson and the Boys and Girls Club of Sells, Arizona to present an optics program on a year-round basis. Boys and Girls Club is a private organization that offers after school and summer programs. We have conducted three semesters of programs at both locations covering a variety of topics in optics, including the law of reflection, multiple reflections and kaleidoscopes, lenses and telescopes, polarization, infrared and ultraviolet light, and optical communication using amplitude modulation.

These modules also form the basis for our week-long optics camps for the Girls Scouts and for underserved Tucson students in the "GEAR-UP" program. These camps provide students with approximately 40 hours of instruction and activities in optics. In this paper, we will provide an outline of our pedagogical approach, specific optics activities, strategies for cooperative learning, learning objectives and misconceptions covered, and a synopsis of assessment approaches. We will discuss the challenges involved with bringing Hands-On Optics to these venues as well as the lessons learned. We will also discuss future plans to make Hands-On Optics a continuing presence at these camps and clubs.

\section{Summary of Hands-On Optics Pedagogical Approach}

The Hands-On Optics program (HOO) provides opportunities for kids to succeed in collaborative learning and problem solving through inquiry-based, hands-on optics activities and projects. HOO increases science and technology knowledge for students, and increases the awareness of optics as a discipline and career that crosses numerous fields. 
There are formative assessment opportunities throughout the modules to gauge student comprehension and these are well suited for the informal camp environment. All of the modules follow a "Learning Cycle" framework (exploration, concept introduction, concept application) similar to that of Karplus and Their (1967) and the BSCS 5 E's instructional model (Bybee, 1997). We have adjusted the learning style framework to one that best fits the target audience. In each module, students explore ideas through hands-on experiences, formulate and test hypotheses, solve problems, and create explanations for what they observe:

Module 1 starts with students engaging a scientific question, "Does light reflect in a predictable manner?" They take data to verify the law of reflection and then extend their new understanding and abilities to a hands-on application called "Hit the Target."

Module 2 begins with students engaging a scientific question, "How do multiple mirror systems work?" They take data to verify predictions and then extend their new understanding and abilities to a hands-on application-building a kaleidoscope.

Module 3 begins with a demonstration to start students investigating how light bends. Through multiple activities they begin to understand image formation using lenses and mirrors. They build a refracting telescope and measure its resolution.

Module 4 begins with students engaging in a scientific question, "What is polarized light and how can it be used?" They collect data to verify their hypotheses then extend their new understanding to the hands-on applications, "I'm Under a Lot of Stress Here" and "Tape Art Challenge." In these activities they analyze stress in plastic materials using polarized light and create colored art using polarization.

Module 5 starts by allowing students to explore the properties of waves using slinkies. The students then learn that visible light comprises only a small portion of the electromagnetic spectrum by attempting to make a model of the EM spectrum. Students then explore different substances and how they interact with infrared, visible and ultraviolet light. Finally, students engage in a series of short activities using infrared and ultraviolet light.

Module 6 engages students in exploring possible answers to the question, "How can we use light to communicate?". Through the "Laser Communication Challenge" activity, they demonstrate understanding of how light can travel through long distances to successfully transmit information.

\section{Optic Camp Learning Objectives and Authentic Assessments}

The turnkey program comprises a comprehensive, ready-to-use collection of six modules, each complete with a toolkit that includes an activity book and all the optics materials needed to allow 30 students to explore and manipulate light in challenging ways. The module titles are Laser Challenges, Kaleidoscope Adventures, Magnificent Magnifications, Peculiar Polarizations, Ultraviolet and Infrared Light, and Communicating over a Beam of Light. Because the activities and kits were developed by educators at an astronomical observatory, many of them have an astronomical focus. As part of their learning objectives within the different HOO modules, participants explore

- Directing laser light to try to hit a target

- Using multiple mirrors to make one of several types of kaleidoscopes

- Forming upside-down images of the world using lenses and mirrors

- Building a telescope

- Using polarized light to navigate like a honeybee and to create art

- Using infrared light to measure temperatures

- Exploring phosphorescence, fluorescence, triboluminescence, and chemiluminescence

- Communicating over a long distance by sending their voices over a beam of light

Although many students attend multiple sessions of our programs, many students attend the sessions intermittently. One technique we have used is to pose a "Question of the Day" that students have to answer at the end of the period. We gave each student a Passport. The Passport contained the student's name, picture, and pages on which to write their answer to each day's question. The Passports provide a record of what students learn during the program. 
Other assessments are built into the modules. For example, the culminating activity of Module 1, "Hit the Target", shows you very quickly if students understand the law of reflection and how to measure angles. Students first position 2 mirrors (then 3 or more) with a laser to hit a stationary target without turning on the laser until the setup is complete. The laser has to be at least 4 feet from the target and one foot away from any mirror.

\section{Hands-On Optics at the Boys and Girls Clubs}

Over the past year the NOAO science education staff has had the opportunity to work with children ages 7 to 14 years old attending the South Tucson and the Sells Boys and Girls Clubs. The children that attend the South Tucson Boys and Girls Club are from the surrounding Hispanic community. The Sells Boys and Girls Club is situated on the Tohono O'odham Indian Reservation, an hour and a half southwest of Tucson. It is in the closest town to Kitt Peak National Observatory. The Boys and Girls Club environment offers an ideal opportunity to provide effective local outreach in optics education, to develop further materials in different informal education settings, and to aid in adapting these materials for use with younger audiences.

\section{Metrics and Logistics}

In South Tucson, two 1.5 hour sessions were held each week over the summer of 2006 . The sessions were delineated by age. One class each week was geared toward 11-14 year olds and the second class each week was adapted to 7-10 year olds. Participation was good: 73 children participated in the program for an average of 22 students each day. There were an equal number of boys and girls participating and twice as many 7-10 year olds as 11-14 year olds. As a capstone, 18 children with the highest attendance record traveled to Kitt Peak National Observatory (run by NOAO) for the Nightly Observing Program at the visitor center telescope.

At the Boys and Girls Club in Sells (on the Tohono O'odham Reservation), 1.5 hour sessions were held every other week during the summer, since travel time was more than 1.5 hours one-way. There were a minimum of 15 children at each session. Their ages were mostly between 7-12 years old. (The older children were attending a newly-opened recreation center nearby.) The HOO program was well received. Of the 37 children who attended, $90 \%$ of them had consistently participated in $\mathrm{HOO}$ and $90 \%$ of them wanted the program to continue.

Many of the same children attending the Fall 2006 HOO sessions at the Boys and Girls Club of South Tucson had experienced Modules 1-6. Therefore, new activities centered on the concepts of making images and optical illusions through hands-on experiments and demonstrations were alpha-tested in 9 out of the 11 weekly Fall classes. During the 11 weeks 57 predominantly Hispanic children $(90 \%)$ ages 7 to 15 years old were reached. On average, 15 children attended per week. Since $80 \%$ of the children were between the ages of 8 and 11 , the activities were developed accordingly to be age-appropriate.

At the Boys and Girls Club in Sells, about half of the children who attended in the summer also attended in the Fall of 2006. The children voted to experience the

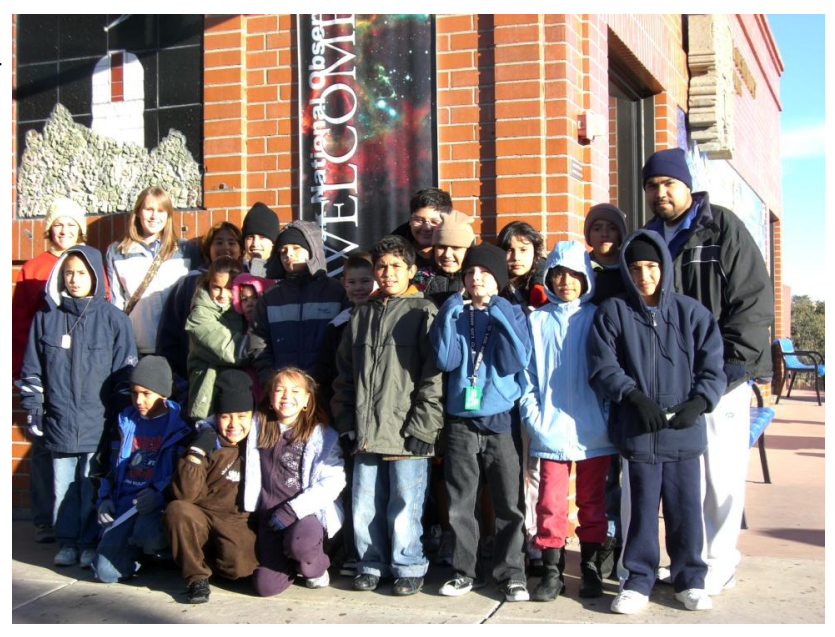

Figure 2. Students from the Boys and Girls Club in South Tucson enjoy the capstone activity for high attendance: a trip to Kitt Peak National Observatory. same content (the $6 \mathrm{HOO}$ Modules) as was offered in the summer. (They enjoyed the lasers in particular.) Sessions took place every other week for $1.5-2$ hours per session. 12 to 15 children on average attended each session for a total of 6 sessions. The children were between 7 and 12 years old and ethnically Native American. One of the last sessions included a special viewing of the transit of Mercury across the Sun through telescopes that used optics now familiar to the students. 
Ethnic Groups in the HOO sessions at the South Tucson Boys and Girls Club

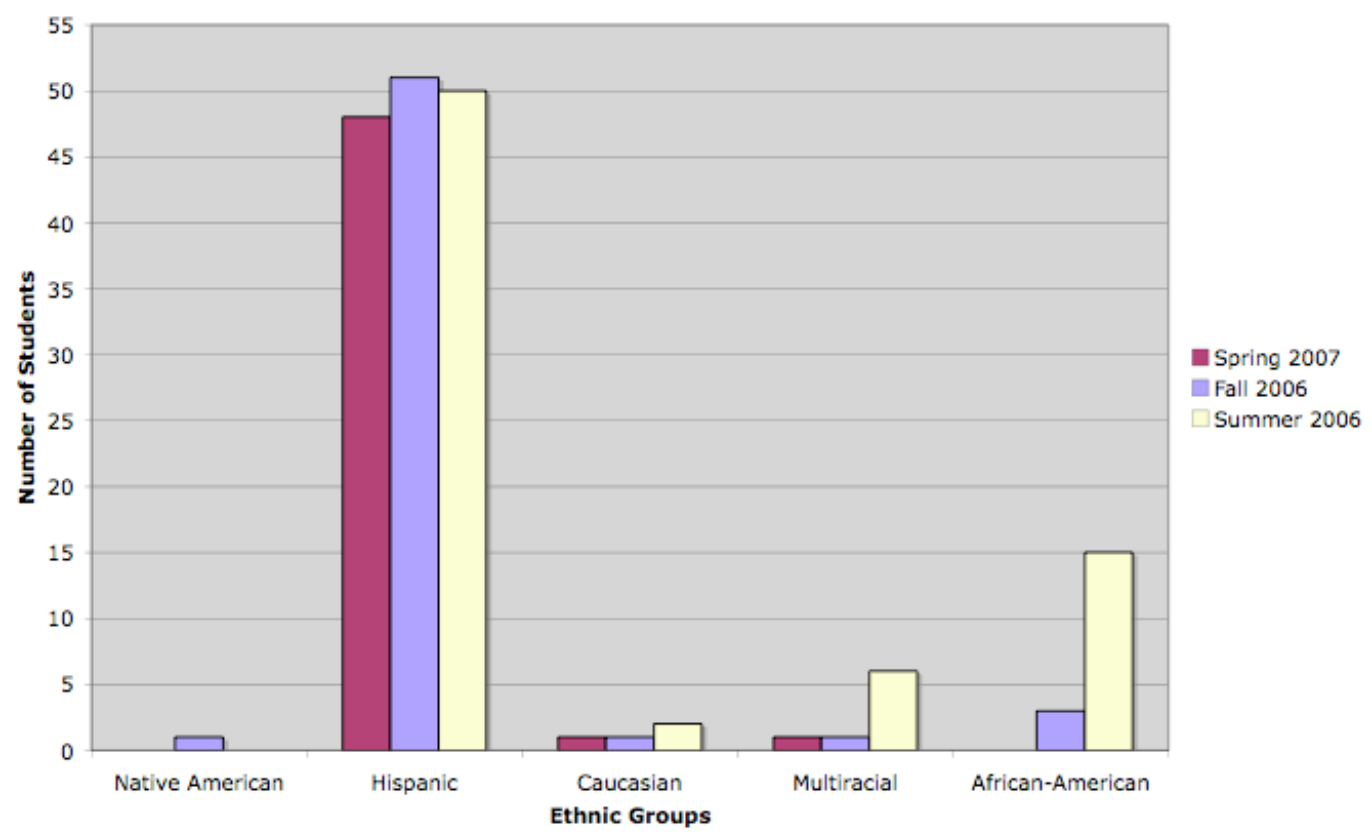

The first bar graph illustrates the majority of the children in the HOO program at the South Tucson Boys and Girls Club are primarily of Hispanic ethnicity: 2 out of 3 children during the Summer of 2006 and 9 or more out of 10 during the ensuing academic year. This can be compared to $100 \%$ of the students in the HOO program at the Sells Boys and Girls Club of Native American ethnicity.

\section{Ages in the $\mathrm{HOO}$ sessions at the South Tucson Boys and Girls Club}

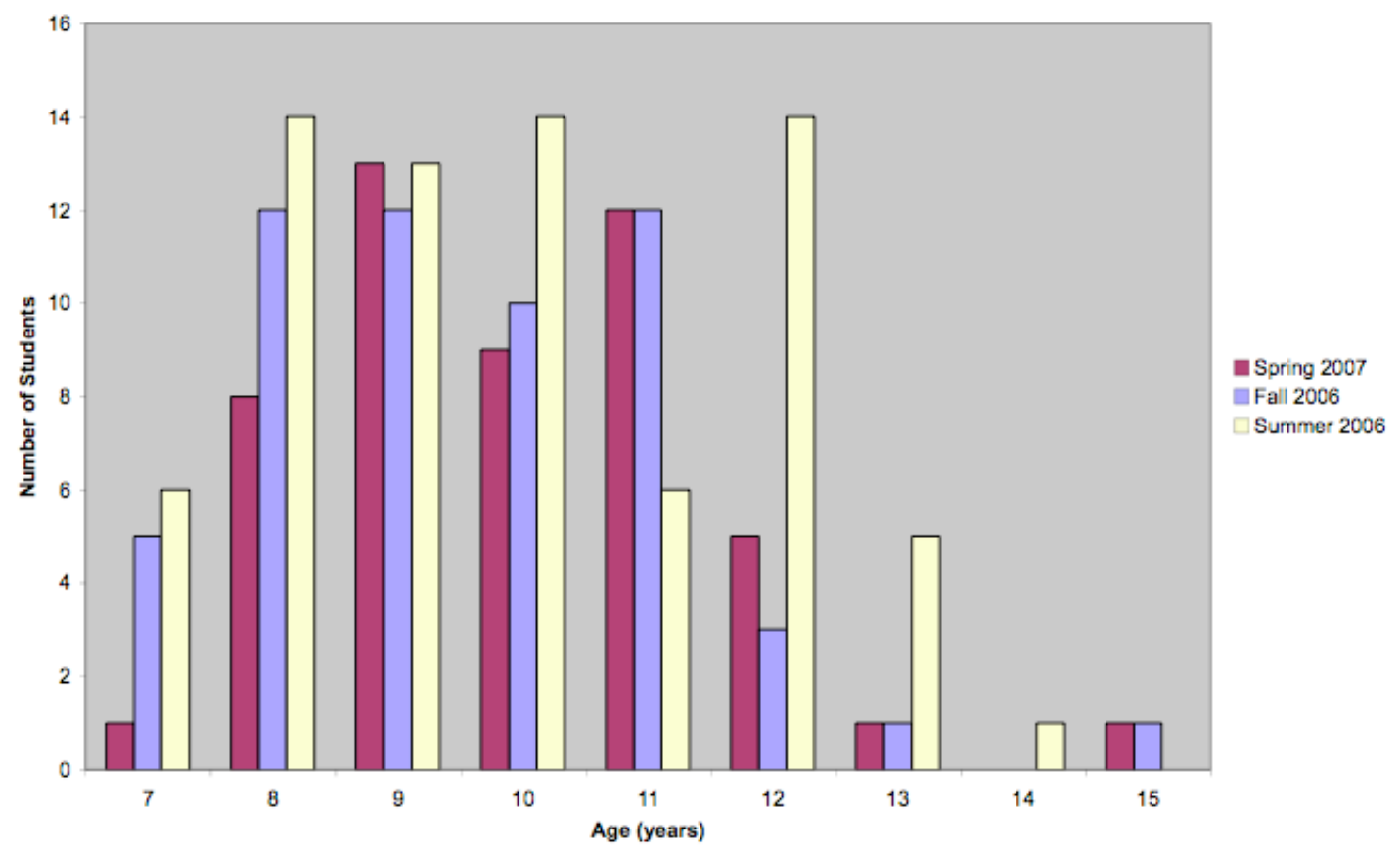

Proc. of SPIE Vol. $966596650 \mathrm{M}-4$ 
The second bar graph illustrates a shift in age demographics between the Summer of 2006 and the ensuing academic year. The number of students in the age range from $12-15$ diminished significantly. The range of ages from 7 to 11 did not change drastically over the three sessions. This presented an opportunity to adapt the once-middle-schoolfocused activities to a younger target audience.

For three months during the Spring of 2007 (mid-January to the end of April), HOO sessions at the Boys and Girls Club in Sells occurred late afternoon every other Wednesday for an hour and a half to 2 hours each time and at the South Tucson Boys and Girls Club every Friday evening for the same length of time. To entice the students at the start of every semester to participate in the HOO program, all the students in South Tucson were invited to a set of optics demonstrations that showcased the upcoming HOO sessions. Subsequently, Modules 1 through 5 were offered in sequence during 12 Spring sessions. By this point, which activities worked best from the first 5 modules were well established as were which were most appropriate for the younger age group. The table below lists the showcase and activities for fourteen 1.5 hour sessions, of which 12 were done during the Spring of 2007.

\section{Boys and Girls Club Spring 2007 Semester Plan}

\begin{tabular}{|c|c|}
\hline Session & $\begin{array}{l}\text { Module: } \\
\text { Activities }\end{array}$ \\
\hline Showcase & $\begin{array}{l}\text { Optics Showcase: } \\
\text { Laser Challenges } \\
\text { Kaleidoscope Adventures } \\
\text { Magnificent Magnifiers } \\
\text { Peculiar Polarizations } \\
\text { Ultraviolet and Infrared Light }\end{array}$ \\
\hline $1^{\text {st }}$ Session & $\begin{array}{l}\text { Laser Challenges: } \\
\text { Laser Stations; Measuring Angles }\end{array}$ \\
\hline $2 n d$ & $\begin{array}{l}\text { Laser Challenges: } \\
\text { Mission Impossible }\end{array}$ \\
\hline $3 r d$ & $\begin{array}{l}\text { Laser Challenges: } \\
\text { Hit the Target }\end{array}$ \\
\hline 4th & $\begin{array}{l}\text { Kaleidoscope Adventures: } \\
\text { Titanium Dioxide, COOKBOOK, Right is Right }\end{array}$ \\
\hline 5 th & $\begin{array}{l}\text { Kaleidoscope Adventures: } \\
\text { Dollar out of Penny, RRReflections }\end{array}$ \\
\hline 6th & $\begin{array}{l}\text { Kaleidoscope Adventures: } \\
\text { Making Kaleidoscopes, Periscopes }\end{array}$ \\
\hline 7 th & $\begin{array}{l}\text { Magnificent Magnifiers: } \\
\text { Light through acrylic block, Focal Point, Focal } \\
\text { Length }\end{array}$ \\
\hline 8 th & $\begin{array}{l}\text { Magnificent Magnifiers: } \\
\text { Simple Magnifiers }\end{array}$ \\
\hline 9th & $\begin{array}{l}\text { Magnificent Magnifiers: } \\
\text { Making Telescopes }\end{array}$ \\
\hline 10th & $\begin{array}{l}\text { Peculiar Polarizations: } \\
\text { Cookie Rack, Stress Tests }\end{array}$ \\
\hline 11th & $\begin{array}{l}\text { Peculiar Polarizations: } \\
\text { Polarization Exploration Stations }\end{array}$ \\
\hline 12th & $\begin{array}{l}\text { Peculiar Polarizations: } \\
\text { Tape Art }\end{array}$ \\
\hline 13th & $\begin{array}{l}\text { Ultraviolet and Infrared Light: } \\
\text { Fluorescence and Phosphorescence Stations }\end{array}$ \\
\hline 14th & $\begin{array}{l}\text { Ultraviolet and Infrared Light: } \\
\text { Tribo- \& Chemiluminescence (e.g., CSI) and } \\
\text { Fluorescent Minerals }\end{array}$ \\
\hline
\end{tabular}




\section{Student Feedback}

Very positive comments about the program were noted by Boys and Girls Club staff members. The main Boys and Girls Club staff member in South Tucson said. "The kids who took the HOO sessions will come up to me at random times to tell me something they learned, and all of them are always asking 'When is science class?' We have a group of 7 year olds who all want to turn 8 so they can take the class."

Another remark from a Boys and Girls staff member was "One new young man who is 11 wasn't really sure he wanted to come to the class, and I told him to try it because I thought he'd like it. Part way through he came over to me and said "this is really cool - I didn't know you could do all this stuff with lasers". These "aha" moments for the kids are the reason it is so important to keep providing them these opportunities you truly are making a difference in the life of these young people by giving them this exposure to science."

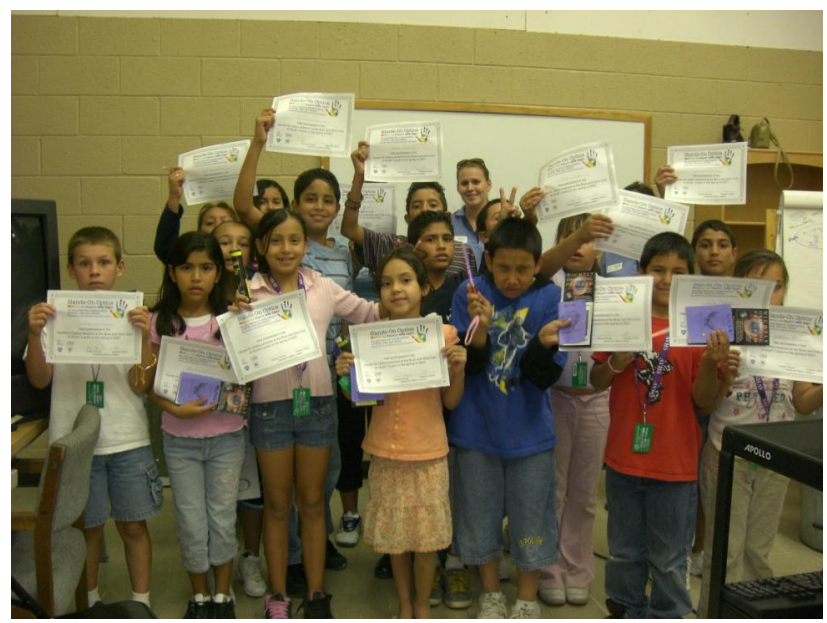

Figure 3. Students from the South Tucson Boys and Girls Club receive their Hands-on Optics "Masters of Reflection" certificates.

An article in the Arizona Daily Star dated October 31, 2006 summarizes the excitement of and effect on the children that the program has had at the Boys and Girls Clubs. See http://www.azstarnet.com/metro/153595.

\section{Extended Optics Camps}

The HOO program "experience" at the Boys and Girls Clubs during this past year (June 2006 to the present) has afforded insight into how to create summer camps on optics. In this section we share our logistical set-up, ideas on the informal curriculum and field trips and facts about the program and the audience it serves.

In Summer 2007, the National Optical Astronomy Observatory (NOAO), in collaboration with BIO5, Tucson Gaining Early Awareness \& Readiness for Undergraduate Programs (GEAR-UP), and the Flandrau Science Center on the University of Arizona (UA) Campus in Tucson, will offer three week-long camp sessions in optics to disadvantaged middle school students. Through a combination of hands-on, inquiry-based science activities, UA campus field trips, and science center experiences, students will be immersed and engaged in the process of doing science via optics and exposed to science resources available at The University of Arizona.

The primary goals of this program are to:

- Engage middle school students in the process of doing optics;

- Excite middle school students about science and technology;

- Expose middle school students who might otherwise be unlikely to attend college to educational opportunities available at The University of Arizona;

- Educate middle school students about career opportunities in optics.

\section{Logistics}

Three week-long summer camp sessions will be held at Flandrau Science Center from June 4-8, June 11-15, and June 18-22, 2007. The camp will run from 9:00 am to 4:00 pm, Monday through Thursday; on Friday, the session will end later in the evening due to a Kitt Peak field trip. Twenty students recruited from GEAR-UP middle schools in Tucson Unified and Sunnyside Unified School Districts will attend each session. A van provided by the camp and driven by the GEAR-UP staff will transport students between their middle school and the UA campus each day. Each week, one full-time teacher and two optics counselors (optics students who have been trained in the HOO curriculum) will lead the camp's activities. In addition, a GEAR-UP coach will be assisting in each camp. Lunch is provided daily at the campus cafeteria. The entire program is free to the students. 


\section{Curriculum}

The Hands-on Optics, minds-on science summer program will utilize the "Hands-on Optics" (HOO) curriculum developed by NOAO. The Hands-on Optics program targets middle school students and is designed to inspire an interest in science and technology by bringing optics-related activities into after-school, summer, and science center programs. The program will utilize its six modules that address basic optics concepts such as reflection, image formation, colors and polarization, ultraviolet and infrared phenomena, and communication over a beam of light. Each day at camp will address a different module and contain exciting challenges and competitions that engage students and allow them to test their newly acquired skills.

In each camp session, HOO module activities and competitions will be supplemented by demonstrations and activities at Flandrau Science Center and a variety of campus field trips. Flandrau Science Center experiences include the Design Garage, in which students will have the opportunity to interact with a set of prototype exhibits, the Planetarium, and the Digital Dome. Potential UA field trip destinations include: the UA Mirror Lab which makes mirrors for telescopes with 8.4 meter objectives, a bio-imaging laboratory, the "cave" (a virtual reality facility at the Learning Technologies Center), the Center for Creative Photography, and the lunar and planetary laboratory. Campus field trips will complement the program's activities and provide the students with much-needed exposure to campus life at The University of Arizona. In addition to daily, on-campus field trips, each camp session will culminate in an evening field trip to Kitt Peak, offered to all campers and their families.

\section{Participants}

About 20 middle school students (incoming $8^{\text {th }}$-graders) from GEAR-UP schools in Tucson Unified and Sunnyside Unified School Districts will attend each week-long camp session. GEAR-UP is a government grant-funded program designed to increase the number of low-income, first-generation college-bound students who are prepared to enter and succeed in postsecondary education. The program serves a cohort of 3,600 students in 14 middle schools in the Tucson and Sunnyside Unified School Districts. GEAR-UP program coordinators have worked with the teachers at these schools to identify the students who will most benefit from this summer science camp experience.

One Day in the Life of an Optics Camp

\section{GEAR-UP Hands-On Optics Camp Day One: Laser Challenges}

$\begin{array}{ll}\text { Time } & \text { Event } \\ \text { 8:00-9:00 } & \text { Arrival }\end{array}$

9:00-9:15 Introductions (Who are we, what is HOO), Icebreaker: "Repeat Game" with name and favorite thing in science

9:15-9:45 Laser Safety, Mission Impossible Teaser The students will try to do mission impossible in groups of 5 without any information on how light reflects. Each group must come up with two questions they'd want to answer by the end of class that would help them do this activity better. Examples: Does light reflect in a predictable manner, if so, how? Does laser light always go in a straight line?

9:45-10:15 Bouncing Ball and Mirror, Mirror on the Wall (in groups) Instead of this being a demonstration, the students will be given the materials and will work together to see if a tennis ball bouncing on a floor is similar to flashlight reflecting from the mirror and if so, how it can be quantified.

10:15-11:15 Measuring Angles and Milky Water Demonstration As written in Module 1, only the main demonstration will be done in a fish tank rather than the small plastic containers 
40 Minutes of group project time:

Group 1: Writing - "Letter to my cousin"

Group 2: Art - create a poster of today's concepts

Group 3: Career - research careers in optics with magazines, book, internet?

Group 4: Math - research the math connections of the day

Group 5: Telescope - spend time building the telescope and writing notes for the next group to continue

11:50-12:00 Morning Wrap-Up

Briefly wrap up morning activities, discuss lunch rules, and discuss field trip details and rules

12:00-12:45 Lunch

1:00-3:00 Field Trip

3:00-3:40 Hit the Target

groups of $4, \sim 5$ minutes to discuss strategy based on what they've learned and what materials they are provided with, $\sim 10$ minutes to do a two mirror setup, $\sim 10$ minutes to do a three mirror setup,

$\sim 10$ minutes for all groups to share strategies

3:40-4:00 Mission Impossible Conclusion, Wrap-up, discussion of next day's acitivties: Magnificent Magnifiers

Mission Impossible will be done with the same 4 groups of 5 as in the morning. The floor will be taped off as shown with the big square measuring $8 \mathrm{ft}$ by $8 \mathrm{ft}$ and each smaller square $4 \mathrm{ft}$ by $4 \mathrm{ft}$.

Each group is in charge of one square.

4:00-5:00 Departure, Deflexion Game

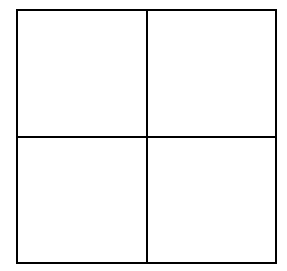

Next Steps for Optics Camps

The optics summer camp program will evolve based on the amount of feedback from the camps in June. In light of that, a similar version of the program is planned for a 4-day optics camps for the Sahuaro Girls Scouts of Tucson at the beginning of August. It will be a resident camp at their Tucson "Hacienda" facility for 40 girls, ages 11-17. Two optics counselors (optics students trained in the HOO curriculum) will lead the camp's activities. A trip to Kitt Peak National Observatory to participate in the Nightly Observing program is being planned as the culminating activity.

\section{Lessons Learned}

A variety of lessons have been learned from our ongoing educational partnership with the Boys and Girls Club. One lesson learned includes being prepared with a translator for every session so that the responsibility does not fall on a young bilingual student who is unfamiliar with the technical terms and is learning the material for the first time. Another lesson learned is to have one person to constantly be responsible for enforcing established classroom rules. A third lesson learned is to spend the first few minutes allowing the students to explore whatever hands-on items are a part of the activity before formally starting the activity. This encourages the students to ask their own questions and find out their own answers. Another lesson learned is to remain aware of the different types of learners especially when assessing their understanding of new concepts. For instance, each student was given a "passport" that had one or two questions on the main concept taught each session. Not only was the way the material was taught important, but how we accepted the answers to assessment questions was equally important. By being sensitive to the different types of learners, the assessment questions in the passport could be answered in words or as a drawing or even verbally. 
On the subject of the passports, students from the Sells Boys and Girls Club had a more challenging time completing the questions. We determined upon observation that some participants were more successful working in groups. Alternative forms of assessment for the Sells Boys and Girls Club is under consideration.

There are a few procedural tweaks to each of the modules that also fall under lessons learned. Instead of listing all of them here, we are in the process of incorporating them into the latest version of the modules. However, here is one example of an on-site adjustment to an activity. To reinforce the concept of light bending as it passes from one medium to another, we did the kinesthetic activity where the students walk at one speed until hitting an imaginary barrier (e.g., concrete to grass or dirt). The first student encountering the barrier walks slower, then the second, then the third, causing the line to "bend" and form a new direction through the new medium. This demonstrates why light moving slower through glass than it does through air, for instance.

\section{Summary and Future Plans for Optics at the Boys and Girls Clubs}

The HOO program has been successful nationally. Our adaptation of the program for local Boys and Girls clubs has also been successful. The national HOO program has laid the framework for major dissemination in Arizona of the Hands-On Optics kits and educational modules and for delivery of the accompanying educator professional development program. NOAO has recently been awarded a Science Foundation of Arizona grant to bring the program, which teams educators with optics industry volunteers, to primarily rural after-school programs to ten rural locations around the state. The Hands-On Optics program will provide kits to these sites and activities suitable for more than 40 hours of informal instruction and relate optics to a variety of technical and scientific fields.

Our proposed program will target rural audiences who historically have been underserved in exposure to science and engineering education programs. HOO will use a volunteer network of technically trained "resource agents" to interact with and mentor the HOO kids at Boys and Girls Clubs. These resource agents can be members of the optics professional societies (Optical Society of America, SPIE-the International Society for Optical Engineering, related technical societies such as IEEE, or member of the optics industry (e.g. Arizona Optics Industry Association). Other technically trained people can also serve as mentors. Graduate and undergraduate students have successfully served as optics resource agents in other locations. The HOO project will team optics "resource agents" with informal science center educators to deliver the HOO project to the target audience. The optics resource agents will also receive training on how best to serve in this role.

\section{Where can I get more information about HOO?}

The Hands-On Optics program actively maintains a web site. The web site lists upcoming events and workshops as well as provides information on how to obtain the kits. You can find our web site at http://www.hands-onoptics.org.

\section{References}

Bybee, R. W. (1997). Achieving scientific literacy: From purposes to practices. Portsmouth, NH: Heinemann.

Karplus, R., \& Thier, H. (1967). A New Look at Elementary School Science. Chicago: Rand-McNally.

Pompea, S. M. and Hawkins, I. (2002). "Increasing Science Literacy in Optics and Photonics through Science Centers, Museums, and Web-based Exhibits", Proceedings of the SPIE: Education and Training in Optics and Photonics, 4588,

Pompea, S. M., Johnson, A., Arthurs, E. and Walker, C. E. (2005a). "Hands-On Optics: An Educational Initiative for Exploring Light and Color in After-School Programs, Museums, and Hands-On Science Centers", Proceedings, Ninth International Topical Meeting on Education and Training in Optics and Photonics, Marseille, France

Pompea, S. M., Walker, C. E. and Peruta, C. (2005b) "Design and Evaluation of Optics Student Competitions and Contests for Maximal Educational Value", Proceedings, Ninth International Topical Meeting on Education and Training in Optics and Photonics, Marseille, France. 